\title{
Efeitos genéticos e de ambiente sobre a produção de leite e a contagem de células somáticas em vacas holandesas ${ }^{1}$
}

\author{
Luana Martins de Andrade ${ }^{2}$, Lenira El Faro ${ }^{3}$, Vera Lucia Cardoso ${ }^{3}$, Lucia Galvão de \\ Albuquerque $^{4,7}$, Laerte Dagher Cassoli ${ }^{5}$, Paulo Fernando Machado ${ }^{6}$
}

\author{
1 Parte do trabalho de graduação da primeira autora apresentado ao Departamento de Zootecnia, FCAV/UNESP, Jaboticabal-SP, realizado \\ com bolsa CNPq/PIBIC. Apoio financeiro: Fundação de Amparo à Pesquisa do Estado de São Paulo - FAPESP. \\ 2 Zootecnista. \\ 3 APTA/SAA-SP, PRDTA Centro Leste, Ribeirão Preto-SP. \\ 4 FCAV/UNESP, Jaboticabal-SP. \\ 5 Gerente Técnico, Clínica do Leite, Piracicaba-SP. \\ 6 Depto. Zootecnia, ESALQ/USP, Piracicaba-SP. \\ 7 Pesquisador do CNPq.
}

RESUMO - Visando estudar as associações genéticas e fenotípicas entre a contagem de células somáticas (CCS) e a produção de leite até 305 dias (P305) e avaliar as perspectivas de utilização da CCS como critério de seleção em bovinos leiteiros, utilizaram-se dados obtidos pelo Programa de Análise da Eficiência de Rebanhos Leiteiros e da Qualidade do Leite, desenvolvido pelo Laboratório de Qualidade do Leite da ESALQ - USP. Por não apresentar distribuição normal, a contagem de células somáticas (CCS) foi transformada para uma escala logarítmica (ECS). Foram estimados os parâmetros genéticos para a P305 dias e a média dos escores de células somáticas (MECS). A média da produção de leite até 305 dias foi de 7.519,51 kg e a da MECS, de 4,04. As herdabilidades estimadas para P305 e MECS foram de 0,22 e 0,13, respectivamente, nas análises univariadas. Valores semelhantes foram estimados pela análise bivariada. A correlação genética entre a P305 e MECS foi de -0,16. Por apresentar correlação genética negativa, mas de baixa magnitude, a seleção para produção de leite não ocasionaria, a princípio, aumento indesejável da MECS.

Palavras-chave: bovinos leiteiros, correlação genética, herdabilidade, mastite

\section{Genetic and environmental effects on milk yield and somatic cell count of Holstein cows}

\begin{abstract}
The objective of this study was to estimate the genetic and phenotypic relationships between somatic cell count (SCC) and milk yield and to evaluate the possibility of using SCC as a selection criteria in breeding programs of dairy cattle. Somatic cell count records were transformed into somatic cell score (SCS) using a logarithmic scale. Genetic parameters for milk yield (305 days) and average somatic cell score (ASCS) were estimated. The overall means for 305-day milk yield (MY305) and ASCS were, respectively, $7519.51 \mathrm{~kg}$ and 4.04. Heritability estimates for MY305 and ASCS, obtained from univariate analyses were 0.22 and 0.13 , respectively. Similar results were obtained from bivariate analysis. The genetic correlation between MY305 and ASCS was -0.16. This result differs from most of those from the literature and suggests that selection for milk yield will not increase ASCS.
\end{abstract}

Key Words: dairy cattle, genetic correlation, heritability, mastitis

\section{Introdução}

Como outros segmentos da sociedade, a produção de leite é uma atividade cada vez mais competitiva. Portanto, é importante buscar ganhos efetivos na quantidade e qualidade do leite produzido.

A qualidade do leite pode ser afetada por vários fatores associados ao manejo, à sanidade, à alimentação, ao potencial genético e a fatores associados à ordenha e ao armazenamento do leite. Contudo, uma das principais causas da queda da qualidade do leite e das perdas quantitativas na produção é a mastite, doença que provoca maior prejuízo à pecuária leiteira no Brasil e em grande parte do mundo. A mastite pode se manifestar nas formas subclínica ou clínica, sendo mais comum a mastite subclínica, que é acompanhada por um aumento na contagem de células somáticas (CCS).

A CCS constitui um importante recurso para o monitoramento da qualidade do leite e da saúde da glândula mamária nos rebanhos, sendo de grande importância por indicar a ocorrência de mastite subclínica e de possíveis 
perdas econômicas dela decorrentes. Para a indústria, este parâmetro se torna ainda mais importante, visto que altas contagens de células somáticas estão associadas a quedas no rendimento na produção de derivados, a alterações organolépticas no leite e derivados e a redução na vida de prateleira (Bruhn \& Franke, 1991; Brito \& Brito, 1998; Klei et al., 1998; Boor, 2001; Santos et al., 2003). Aspectos fisiológicos como a idade da vaca e a fase da lactação também podem alterar a CCS (Harmon, 1994).

A CCS é uma medida que pode ser obtida com relativa facilidade e apresenta estimativas de herdabilidade mais altas que as obtidas para incidência de mastite. A CCS é geralmente expressa em escore de células somáticas (ECS), que é a transformação da CCS para uma escala logarítmica para aproximá-la a uma distribuição normal, com homogeneidade de variâncias (Ali \& Shook, 1980, citados por Magalhães et al., 2006).

Estudos na literatura internacional relatam coeficientes de herdabilidade do ECS variando de 0,08 a 0,17 (Cue et al., 1987; Boettcher et al., 1992; Welter \& Freeman, 1992; Pösö \& Möntysaari, 1996; Rupp \& Boichard, 1999; Carlén et al., 2004; Odegard et al., 2004), enquanto, para a incidência de mastite, este valor é próximo de 0,03 (Pösö \& Mäntysaari, 1996; Carlén et al., 2004; Odegard et al., 2004).

Considerando sua correlação genética relativamente alta com a incidência de mastite (variando em torno de 0,40 a 0,80, segundo revisão de Shook \& Schutz, 1994), a contagem de células somáticas (CCS) tem sido usada como indicador da resistência à mastite em programas de seleção de gado de leite (Mrode \& Swanson, 1996).

Segundo Pösö \& Mäntysaari (1996), a produção de leite é positivamente correlacionada à ocorrência de mastite clínica e ao ECS, especialmente na primeira lactação, embora associações genéticas negativas também tenham sido relatadas entre o ECS e a produção de leite, especialmente para a segunda lactação ou lactações posteriores. Outros pesquisadores (Emanuelson et al., 1988; Boettcher et al., 1992; Welter \& Freeman, 1992; Gadini et al., 1997; Rupp \& Boichard, 1999; Carlen et al., 2004) encontraram valores baixos e positivos (0 a 0,22), que, apesar da baixa magnitude, podem indicar que vacas com altos valores genéticos para produção de leite tendem a ser mais suscetíveis à mastite e que a incidência de mastite pode aumentar como resposta à seleção para produção de leite. Na Finlândia, Koivula et al. (2005) obtiveram correlação genética positiva entre CCS e produção de leite na primeira lactação, mas, apesar desses resultados, encontraram valores negativos ou próximos de zero na segunda lactação, indicando que a seleção para redução da CCS na primeira lactação pode não afetar a produção de leite nas lactações subseqüentes. Resultados semelhantes foram obtidos por Pösö \& Mäntysaari (1996), que verificaram correlações genéticas de $-0,10$ e 0 para a segunda e terceira lactações,respectivamente. Banos \& Shook (1990) encontraram valores positivos para esta correlação na primeira lactação, variando de 0,20 a 0,31, de acordo com diferentes níveis de CSS de rebanhos e valores negativos para a segunda e terceira lactações $(-0,06$ a $-0,29)$.

Objetivou-se neste trabalho estimar os componentes de variância para a produção de leite até 305 dias e para a média do escore de células somáticas de lactações de vacas holandesas e estudar as associações genética e fenotípica entre estas características, visando fornecer subsídios para sua utilização em programas de melhoramento genético.

\section{Material e Métodos}

A estimativa dos parâmetros genéticos para a média da CCS e a P305 dias foi realizada por meio do estudo de 4.856 registros de produções de leite até 305 dias e de 3.918 registros de médias dos escores de células somáticas (MECS), pertencentes a 4.144 e 3.428 vacas, respectivamente. Os dados foram provenientes de vacas da raça holandesa pertencentes a rebanhos localizados na Região Sudeste, principalmente do estado de São Paulo, obtidos pelo Programa de Análise de Rebanhos Leiteiros e da Qualidade do Leite da ESALQ - USP no período de 1999 a 2002.

Para a formação dos arquivos, foram mantidas lactações com, no mínimo, três controles contendo informação de CCS. Por não apresentar distribuição normal, a contagem de células somáticas (CCS) foi transformada para uma escala logarítmica em escore de células somáticas (ECS), conforme recomendado por Sechrist (1985), com base no procedimento desenvolvido por Shook (1982): ECS $=\log _{2}$ (CCS/ 100) + 3. A média do ECS foi obtida pela média aritmética dos ECS de todos os controles da lactação. Inicialmente, para o estudo dos efeitos fixos que afetam a produção de leite e a CCS na lactação, foram realizadas análises preliminares pelo método de quadrados mínimos, utilizando-se o procedimento GLM (SAS, 1996).

Nos modelos incluíram-se apenas os efeitos fixos de grupo contemporâneo (GC), como variável classificatória, e os efeitos da duração da lactação e da idade da vaca ao parto (IDV), como covariáveis, sendo testados os efeitos linear e quadrático. A idade da vaca ao parto (IDV) foi considerada em meses e variou de 20 a 140 meses, o que correspondeu a ordens do primeiro ao nono parto. A variável GC foi criada considerando-se as interações dos 
efeitos de rebanho-ano-mês do parto contendo 490 níveis para P305 e 417 níveis para MECS. Foram eliminados do arquivo de dados os GC com menos de três observações.

Para a estimativa dos componentes de variância para a P305 e para a MECS, foram usados modelos animais univariados e bivariados que contiveram, além dos efeitos fixos citados anteriormente, os efeitos aleatórios genético aditivo e de ambiente permanente de animal.

$\mathrm{Na}$ forma matricial, o modelo é representado por:

$$
\mathrm{y}=\mathrm{Xb}+\mathrm{Wp}+\mathrm{Za}+\mathrm{e}
$$

em que: $\mathrm{y}=$ vetor da produção de leite acumulada até 305 dias ou MECS; $b=$ vetor de soluções para os efeitos fixos contendo grupo contemporâneo e as covariáveis idade ao parto e duração da lactação; $p=$ vetor de soluções para o efeito aleatório de ambiente permanente; $a=$ vetor de soluções para o efeito aleatório genético aditivo; $\mathrm{X}, \mathrm{Z}, \mathrm{W}=$ matrizes de incidência para os efeitos fixos, genético-aditivo e de ambiente permanente, respectivamente; e = vetor de resíduos aleatórios.

As pressuposições em relação aos componentes dos modelos para as análises bivariadas são:

$$
E\left[\begin{array}{l}
y \\
a \\
p \\
e
\end{array}\right]=\left[\begin{array}{l}
X b \\
0 \\
0 \\
0
\end{array}\right] ; \quad \mathrm{e}\left[\begin{array}{l}
a \\
p \\
e
\end{array}\right]=\left[\begin{array}{lll}
G & 0 & 0 \\
0 & P & 0 \\
0 & 0 & R
\end{array}\right],
$$

em que: $\mathrm{G}=\mathrm{A} \otimes \mathrm{G}_{0}$ é a matriz de (co)variâncias genéticas aditivas entre as características; $\mathrm{P}=\mathrm{I} \otimes \mathrm{P}_{0}$, a matriz de (co)variâncias de ambiente permanente entre as caracterís- ticas; $R=I \otimes R_{0}$, a matriz de (co)variâncias residuais entre as características.

Os componentes de variância foram estimados pelo método da máxima verossimilhança restrita, utilizando-se um algoritmo livre de derivadas disponível no pacote MTDFREML (Boldman et al., 1993).

\section{Resultados e Discussão}

A média observada e o desvio-padrão para P305 foram $7.519,51$ e $2.187,45 \mathrm{~kg}$, respectivamente, e, para a MECS, 4,04 e 1,70. Os coeficientes de variação para P305 e MECS foram, respectivamente de 29,09 e $42,10 \%$. Os resultados da análise de variância pelo método de quadrados mínimos para a P305 e MECS podem ser visualizados na Tabela 1. Todos os efeitos incluídos no modelo para a P305 foram significativos $(\mathrm{P}<0,01)$, sendo que apenas o efeito linear da duração da lactação influenciou significativamente a produção. Para a MECS houve efeito significativo de GC e idade da vaca ao parto $(\mathrm{P}<0,01)$.

Os coeficientes de regressão linear e quadrático da MECS sobre a idade da vaca foram, respectivamente, de 0,0508 e -0,000224, evidenciando tendência de aumento dos escores médios de células somáticas com o aumento da idade da vaca, atingindo o máximo em torno dos 110 meses de idade (Figura 1). Observa-se nessa curva um comportamento praticamente linear na relação entre MECS e a idade ao parto. Segundo Reneau (1986), isso indica que, à medida que as vacas envelhecem, aumenta a oportunidade de exposição a agentes causadores de mastite, com tendência

Tabela 1 - Resumo da análise de variância da produção de leite até 305 dias (P305) e da média dos escores de células somáticas (MECS) pelo método de quadrados mínimos

Table 1 - Summary of analyses of variance for 305- day milk yield (M305) and for average somatic cell score (ASCS) by the least squares method

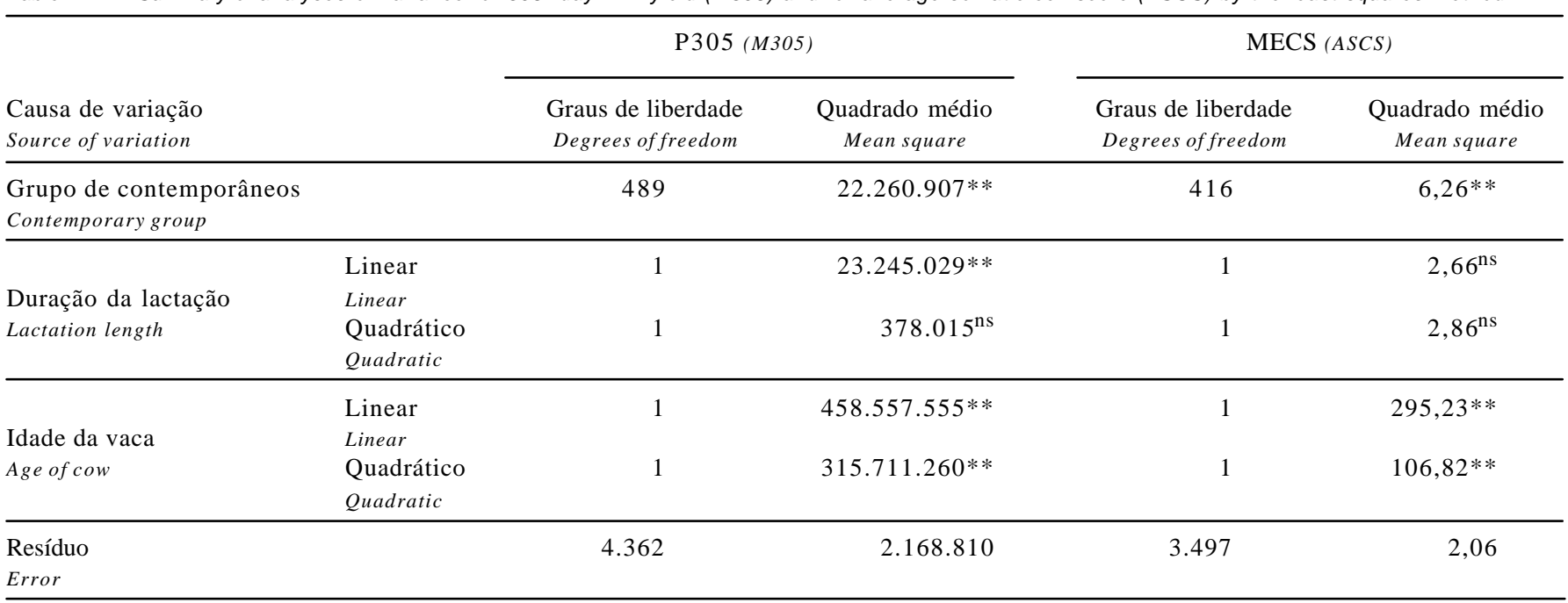

** Significativo $(P<0,01) ; \mathrm{ns}=$ não-significativo.

** Significant $(P<0.01) ; n s=$ not significant. 


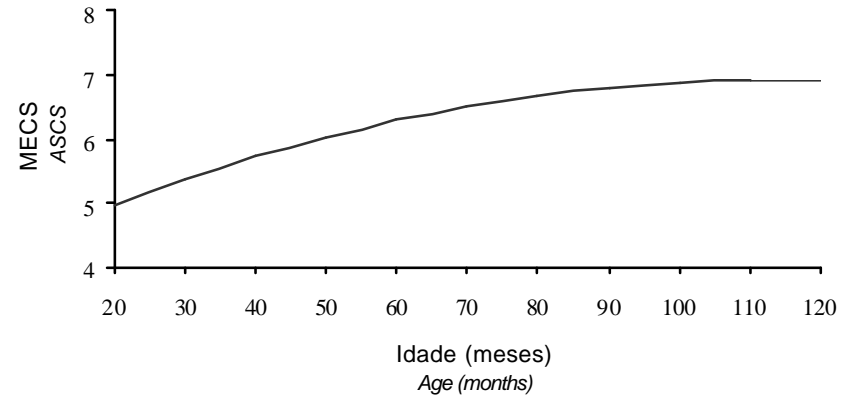

Figura 1 - Efeito da idade da vaca ao parto sobre o escore de células somáticas (MECS) no leite.

Figure 1 - Average somatic cell score (ASCS) according to age at calving.

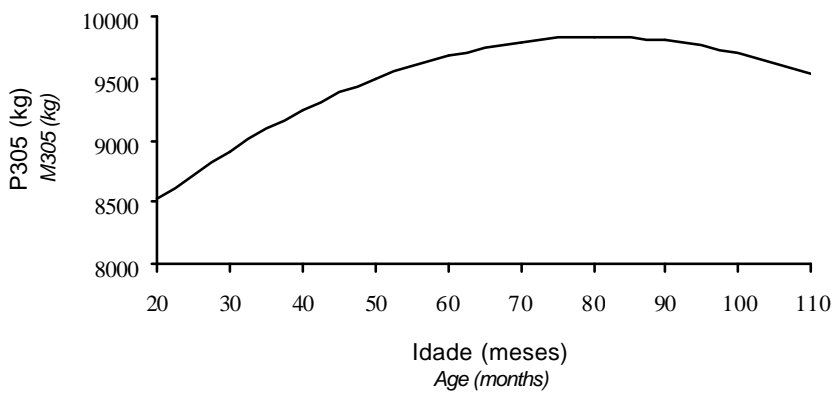

Figura 2 - Efeito da idade da vaca ao parto sobre a curva da produção de leite até 305 dias (P305) de lactação.

Figure 2 - Regression of 305-day milk yield (M305) on age at calving.

de infecções mais prolongadas e maior prejuízo para os tecidos da glândula mamária. Em estudo prévio usando parte desse conjunto de dados, Magalhães et al. (2006) observaram que vacas mais velhas, a partir da 4 a lactação, apresentavam maiores CCS.

Quanto à produção de leite, também houve aumento à medida que a vaca se aproximou da idade adulta (Figura 2). Os coeficientes de regressão linear e quadrático da P305 sobre a idade da vaca ao parto foram, respectivamente, de 57,44 e $-0,355 \mathrm{~kg}$. O pico da produção de leite da vaca foi atingido em torno de 80 meses ou 6,6 anos de idade, que corresponderia, aproximadamente, à $4 \underline{a}$ ou $5 \underline{a}$ lactação, como observado por Torres et al. (2000), que obtiveram produção de leite máxima em vacas holandesas por volta dos 73 aos 78 meses de idade, e Magalhães et al. (2006).

Os componentes de variância e os parâmetros genéticos para a P305 e MECS podem ser observados nas Tabelas 2 e 3. Para a P305, as variâncias genéticas foram maiores que as de ambiente permanente, revelando que o efeito de ambiente permanente teve menor contribuição na variabilidade da P305. Por outro lado, para a média dos escores, o efeito de ambiente permanente foi maior que a variância genética. As variâncias de ambiente temporário foram maiores que as aditivas e de ambiente permanente, como era esperado, haja vista o grande número de rebanhos, sugerindo a existência de ambientes diferentes entre os sistemas de produção estudados. Os componentes de variância foram muito próximos para as análises uni e bivariadas.

A herdabilidade estimada para a P305 foi de $0,22 \mathrm{em}$ ambas as análises uni e bivariada. Es ta estimativa corrobora os resultados da literatura para a raça Holandesa, cujos valores tem variado de 0,17 a 0,39 (Meyer et al., 1989; Boettcher et al., 1992; Welter \& Freeman, 1992; Gadini et al., 1997; Machado, 1999; Freitas et al., 2001; Ferreira et al., 2003).

A herdabilidade estimada para MECS neste estudo foi de 0,13 em ambas as análises. Este valor é próximo ao observado na literatura (Mrode \& Swanson, 1996; Gadini et al., 1997; Rupp \& Boichard, 1999) e, por ser de baixa magnitude, indica que é mais fácil obter ganhos na CCS melhorando o ambiente (manejo na ordenha, limpeza dos tetos, nutrição) que por meio de seleção. Entretanto, mesmo que o ganho via seleção seja menor, isso não significa que ela não seja importante, haja vista o impacto econômico da CCS para os sistemas de produção de leite. Por isso, deve-se realizar um trabalho intenso de seleção de animais mais resistentes, além de melhoria do ambiente.

As covariâncias genéticas, de ambiente temporário e fenotípica entre a P305 e MECS foram negativas (Tabela 3). A correlação genética entre a P305 e MECS neste estudo foi de $-0,16$ e, embora de baixa magnitude, indica relação favorável entre essas características. Este resultado sugere que a seleção para a produção de leite poderia diminuir a MECS ou que animais de maior valor genético para a produção de leite seriam os mais resistentes à mastite.

O resultado observado neste estudo diferiu da maioria dos encontrados na literatura, em que as correlações são positivas e próximas de 0,20 (Emanuelson et al., 1988; Boettcher et al., 1992; Welter \& Freeman, 1992; Gadini et al., 1997; Rupp \& Boichard, 1999; Carlen et al., 2004). Contudo, em estudos onde as correlações foram estimadas a partir de conjuntos de dados de primeiras, segundas e terceiras lactações separadamente, houve tendência de correlações positivas na primeira lactação e negativas ou próximas de zero nas lactações subseqüentes (Banos \& Shook, 1990 ; Pösö \& Mäntysaari, 1996; Koivula et al., 2005). Banos \& Shook (1990) obtiveram resultados que variaram de 0,31 (primeira lactação) a -0,29 (terceira lactação), semelhantes aos obtidos neste trabalho. Segundo esses autores, o descarte de vacas de primeira lactação com base na produção de leite, na incidência de mastite ou ambas as características pode influenciar a correlação genética nas lactações 
Tabela 2 - Estimativas de variancias genética $\left(\sigma^{2}{ }_{a}\right)$, de ambiente permanente $\left(\sigma_{p}^{2}\right)$ e de ambiente temporário $\left(\sigma^{2}{ }_{e}\right)$ e coeficientes de herdabilidade $\left(h^{2}\right)$ para a produção de leite até 305 dias (P305) e para a média dos escores de células somáticas (MECS) obtidos em análise uni e bivariada

Table 2 - Estimates of genetic $\left.\sigma^{2}{ }_{a}\right)$, permanent environmental $\left.\sigma^{2}{ }_{p}\right)$, residual $\left(\sigma^{2}\right)$ variances and heritability $\left(h^{2}\right)$ estimates for 305 day milk yield (M305) and average somatic cell score (ASCS), by univariate and bivariate analyses

\begin{tabular}{|c|c|c|c|c|}
\hline \multirow[b]{2}{*}{$\begin{array}{l}\text { Característica } \\
\text { Trait }\end{array}$} & \multicolumn{4}{|c|}{$\begin{array}{c}\text { Análise univariada } \\
\text { Univariate analysis }\end{array}$} \\
\hline & ca $\sigma_{a}^{2}$ & $\sigma_{p}^{2}$ & $\sigma_{\mathrm{e}}^{2}$ & $\mathrm{~h}^{2}$ \\
\hline \multirow{3}{*}{$\begin{array}{l}\text { P305 } \\
\text { M305 } \\
\text { MECS } \\
\text { ASCS }\end{array}$} & $489.202,88$ & $426.058,09$ & $1.287 .043,37$ & $0,22(0,00)$ \\
\hline & 0,269 & 0,617 & 1,196 & $0,13(0,05)$ \\
\hline & \multicolumn{4}{|c|}{$\begin{array}{l}\text { Análise bivariada } \\
\text { Bivariate analysis }\end{array}$} \\
\hline $\begin{array}{l}\text { P305 } \\
\text { M305 }\end{array}$ & $488.735,80$ & $430.859,98$ & $1.283 .134,57$ & 0,22 \\
\hline $\begin{array}{l}\text { MECS } \\
\text { ASCS }\end{array}$ & 0,267 & 0,630 & 1,191 & 0,13 \\
\hline
\end{tabular}

subseqüentes. Práticas de descarte removeriam as vacas de baixa produção ou vacas de alto potencial para produção, com mastite clínica ou altas CCS.Conseqüentemente, vacas de alta produção e baixas CCS seriam favorecidas e, tendo a oportunidade de produzir outras lactações, proporcionariam correlações genéticas negativas e favoráveis entre estas características.

Independentemente de a correlação ser positiva ou negativa, a maioria das estimativas de correlação genética entre a produção de leite e a CCS é de pequena magnitude, o que poderia indicar, a princípio, que a seleção para a P305 tem pouca ou nenhuma influência sobre a resistência à mastite. Isso, de certo modo, é também favorável, pois, na ausência de índices de seleção para a escolha de reprodutores que otimizem o retorno econômico esperado de suas filhas, o uso da característica P305 como critério principal de seleção, seguida da CCS, pode resultar em aumento da resistência à mastite do rebanho.

A correlação fenotípica entre MECS e P305 foi de -0,15, bem próxima à correlação genética. Resultados semelhantes foram encontrados por Monardes et al. (1984), Boettcher et al. (1992) e Pösö \& Mäntysaari (1996). Outros autores (Banos \& Shook, 1990) estimaram valores de -0,04 (primeira lactação) a-0,19 (terceira lactação), de acordo com diferentes níveis de CCS média dos rebanhos. Em revisão de Mrode \& Swanson (1996), são descritos resultados de -0,08 a -0,20. Esta correlação negativa indica que vacas com altas CCS podem ter a produção de leite reduzida, o que foi constatado em vários estudos (Philpot, 2002; Magalhães et al., 2006). Philpot (2002) afirmou, com base em dados do National Mastitis Council, Estados Unidos, que a mastite custa ao produtor leiteiro aproximadamente US\$180/vaca/ano. Esse custo está associado a uma perda de $2,5 \%$ na produção de leite para cada 100.000 células somáticas/mL acima do nível basal de 200.000 células/mL. No estudo de Magalhães et al. (2006), foi observada relação linear negativa entre estas características. Os autores relataram, exceto para a primeira lactação, na qual as perdas não foram significativas, que o aumento na CCS causou perdas consideráveis na P305.

A correlação de ambiente permanente foi praticamente zero, sugerindo que as práticas de manejo realizadas nos rebanhos para prevenir ou tratar a mastite têm sido adequadas, não propiciando efeitos permanentes danosos no tecido mamário dos animais.

Altas CCS interferem nas características do leite importantes para a indústria de derivados lácteos, podendo resultar em aumento do tempo de coagulação do leite, diminuição da firmeza do coágulo, maior perda de componentes do leite para o soro, menor rendimento de fabricação, defeitos de textura e alteração das características organolépticas (Santos et al., 2003). Além das perdas para a indústria, devem serconsidera das também as perdas na produção de leite decorrentes do aumento da CCS, ou seja, as perdas que ocorrem no sistema de produção quando o animal apresenta a mastite subclínica ou clínica. Essas perdas podem ser ocasionadas pelo descarte do leite de animais doentes, pelos custos com tratamentos, pela perda de tetos saudáveis, pelo descarte involuntário dos animais ou pela contaminação de animais saudáveis do rebanho, o que significa menor retorno econômico para o produtor, tanto pela redução na produção como pelas penalidades aplicadas pelos laticínios. Com a implementação da Instrução Normativa no. 51 (MAPA, 2002), tem-se verificado maior rigor no controle de qualidade do leite e, portanto, a contagem de células somáticas passa a ter grande importância como critério de seleção nos programas de melhoramento genético, mesmo sendo uma característica de baixa herdabilidade.

\section{Conclusões}

As estimativas de herdabilidade para a produção de leite até 305 dias obtidas por análises univariada e bivariada indicam a possibilidade de ganho genético para essa característica mediante seleção.

A estimativa de herdabilidade da característica MECS evidencia que, embora as práticas de manejo adequado sejam importantes para o controle adequado da ocorrência 
Andrade et al.

Tabela 3 - Estimativas de covariâncias e correlações genética, de ambiente permanente, de ambiente temporário e fenotípica entre a produção de leite e o escore médio de células somáticas obtidas em análise bivariada

Table 3 - Estimates of genetic, permanent environmental, temporary environmental and phenotypic covariances and correlations between 305-day milk yield and average somatic cell score by bivariate analysis

\begin{tabular}{lccc}
\hline $\begin{array}{l}\text { Efeito } \\
\text { Effect }\end{array}$ & $\begin{array}{c}\text { Ggenético aditivo } \\
\text { Aditive genetic }\end{array}$ & $\begin{array}{c}\text { Ambiente permanente } \\
\text { Permanent environmental }\end{array}$ & $\begin{array}{c}\text { Ambiente temporário } \\
\text { Temporary environmental }\end{array}$ \\
\hline $\begin{array}{l}\text { Covariância } \\
\begin{array}{l}\text { Covariance } \\
\text { Correlação }\end{array}\end{array}$ & $-59,35$ & 16,62 & $-275,46$ \\
$\begin{array}{l}\text { Correlation } \\
\text { Phenotypic }\end{array}$ & $-0,16$ & 0,03 & $-0,22$ \\
\hline
\end{tabular}

de mastite nos rebanhos leiteiros, existe uma variação genética aditiva para esta característica, ainda que de pequena magnitude.

A correlação genética negativa entre a MECS e a P305 indica relação favorável entre estas características para a população estudada, devendo, no entanto, ser considerada com cautela.

\section{Literatura Citada}

BANOS, G.; SHOOK, G.E. Genotype by environment interaction and genetic correlations among parities for somatic cell count and milk yield. Journal of Dairy Science, v.73, n.9, p.25632573, 1990

BOLDMAN, K.; KRIESE, L.; Van VLECK, L.D. A manual for use of MTDFREML: a set of programs to obtain estimates of variances and covariances (DRAFT). Lincoln: Department of Agriculture, Agriculture Research Service, 1993. 120p.

BOETTCHER, P.J.; HANSEN, L.B.; VAN RADEN, P.M. et al. et al. Genetic evaluation of Holstein bulls for somatic cell in milk of daughters. Journal of Dairy Science, v.75, p.1127, 1992.

BOOR, K.J. Fluid dairy product quality and safety: looking to the future. Journal of Dairy Science, v.84, n.1, p.1-11, 2001.

BRASIL. Ministério da Agricultura, Pecuária e Abastecimento. Instrução Normativa $\mathrm{n}^{\circ} 51$, de 18 de setembro de 2002. Regulamento Técnico de produção, identidade e qualidade do leite de cabra. Diário Oficial da União. Brasília: 2002. 55p.

BRITO, M.AV.P.; BRITO, J.R.F. O efeito da mastite no leite. Revista Leite Brasil, v.1, n.4, 1998.

BRUHN, J.; FRANKE, A.A. Raw milk composition and cheese yield in California: 1987 and 1988. Journal of Dairy Science, v.74, n.3, p.1108-1114, 1991

CARLÉN, E.; STRANDBERG, E.; ROTH, A. Genetic parameters for clinical mastitis, somatic cell counts and production in the three first lactation of Swedish Holstein cows. Journal of Dairy Science, v.87, n.9, p.3062-3070, 2004.

CUE, R.I.; MONARDES, H.G; HAYES, J.F. Correlations between production traits in first lactation Holstein cows. Journal of Dairy Science, v.70, n.10, p.2132-2137, 1987.

EMANUELSON, U.; DANELL, B.; PHILIPSSON, J. Genetic parameters for clinical mastitis, somatic cell counts, and milk production estimated by multiple trait restricted maximum likelihood. Journal of Dairy Science, v.71, p.467-476, 1988 .

FERREIRA, W.J.; TEIXEIRA; N.M.; EUCLYDES, R.F. et al. Avaliação genética de bovinos da raça Holandesa usando a produção de leite no dia do controle. Revista Brasileira de Zootecnia, v.32, n.2, p.295-303, 2003.

FREITAS, A.F.; DURÃES, M.C.; VALENTE, J. et al. Parâmetros genéticos para as produções de leite e gordura na três primeiras lactações de vacas da raça Holandesa. Revista Brasileira de Zootecnia, v.30, n.3, p.709-713, 2001.

GADINI, C.H.; KEOWN, J.F.; Van VLECK, L.D. Parâmetros genéticos das produções de leite, gordura e proteína, e do escore de células somáticas em 305 dias de produção. In: REUNIÃO ANUAL DA SOCIEDADE BRASILEIRA DE ZOOTECNIA, 34. 1997, Juiz de Fora. Anais... Juiz de Fora: Sociedade Brasileira de Zootecnia, 1997. v.3, p.47-49.

HARMON, R.J. Physiology of mastitis and factors affecting somatic cell counts. Journal of Dairy Science, v.77, n.7, p.2003-2212, 1994.

KLEI, L.; YUN, J.; SAPRU, A. et al. Effects of somatic cell count on cottage cheese yield and quality. Journal of Dairy Science, v.81, n.5, p.1205-1213, 1998.

KOIVULA, M.; MÄNTYSAARI, E.A.; NEGUSSIE, E. et al. Genetic and phenotypic relationships among milk yield and somatic cell count before and after clinical mastitis. Journal of Dairy Science, v. 88, p.827-833, 2005.

MACHADO, S.G.; FREITAS, M.A.R.; GADINI, C.H. Genetic parameters of test-day milk yields of Holstein cows. Genetics and Molecular Biology, v.22, n.3, p.383-386, 1999.

MAGALHÃES, H.R.; EL FARO, L.; CARDOSO, V.L. et al. Influência de fatores de ambiente sobre a contagem de células somáticas e sua relação com perdas na produção de leite de vacas da raça Holandesa. Revista Brasileira de Zootecnia, v. 35, n. 2, p. $415-421,2006$.

MEYER, K.; GRASER, H.U.; HAMMOND, K. Estimates of genetic parameters for first lactation test day production of Australian Black and White cows. Livestock Production Science, v.21, p.177-199, 1989.

MONARDES, H.G.; HAYES, J.F.; MOXLEY, J.E. Heritability of lactation cell count measures and their relationships with milk yield and composition in Ayrshire cows. Journal of Dairy Science, v.67, p.124-129, 1984

MRODE, R.A.; SWANSON, G.J.T. Genetic and statistical properties of somatic cell count and its suitability as an indirect means of reducing the incidence of mastitis in dairy cattle. Animal Breeding Abstracts, v.64, n.11, p.847-857, 1996.

ØDEGÅRD J.; HERINGSTAD B.; KLEMETSDAL, G Bivariate genetic analysis of clinical mastitis and somatic cell count in Norwegian dairy cattle. Journal of Dairy Science, v.87, n.10, p.3515-3517, 2004

PHILPOT, W.N. Qualidade do leite e controle de mastite: passado, presente e futuro. In: CONGRESSO PANAMERICANO DE QUALIDADE DO LEITE E CONTROLE DA MASTITE, 2., 2002, Ribeirão Preto. Anais... Ribeirão Preto, 2002. p.23-38.

PÖSÖ, J.; MÄNTYSAARI, E.A. Relationships between clinical mastitis, somatic cell score, and production for the first three lactations of Finnish Ayrshire. Journal of Dairy Science, v.79, p.1284-1291, 1996.

RENEAU, J.K. Effective use of dairy herd improvement somatic cell counts in mastitis control. Journal of Dairy Science, v.69, p.1708-1720, 1986. 
RUPP, R.; BOICHARD, D. Genetic parameters for clinical mastitis, somatic cell score, udder type traits and milk ease in first lactation Holsteins. Journal of Dairy Science, v.82, n.10, p.2198-2204, 1999.

SANTOS, M.V.; MA, Y.; BARBANO, D.M. Effect of somatic cell count on proteolysis and lipolysis in pasteurized fluid milk during shelf-life storage. Journal of Dairy Science, v.86, n. 8, p.2491-2503, 2003.

STATISTICAL ANALYSIS SYSTEM - SAS. User's guide : statistics. Cary: 1996. 842p.

SHOOK, G.E. Approaches to summarizing somatic cell count which improve interpretability. In: ANNUAL MEETING NATIONAL MASTITIS COUNCIL, 2., 1982, Arlington. Proceedings... Arlington: 1982. p.150.
SHOOK, G.E.; SCHUTZ, M.M. Selection on somatic cell score to improve resistance to mastitis in the United States. Journal of Dairy Sciences, v.77, p.648-658, 1994.

TORRES, R.A.; ARAÚJO, C.V.; COSTA, C.N. et al. Ajustamento da produção de leite para os efeitos simultâneos de ordem, idade e estação de parto. Revista Brasileira de Zootecnia, v.29, n.6, p.2253-2259, 2000.

WELTER, R.D.; FREEMAN, A.E. Genetic parameters for yield traits of Holstein including lactose and somatic cell score. Journal of Dairy Science, v.75, p.1342-1348, 1992. 